\title{
Total Syntheses of Echinopines A and B, Sesquiterpenes with a Unique Tetracyclic [3-5-5-7] Skeleton
}

\author{
Youssouf Sanogo a, Luca Allievi a , Camille Lecourt ${ }^{\text {a }}$, Sabrina Dhambri ${ }^{\text {a }}$, Janick Ardisson ${ }^{\text {a }}$, Geoffroy Sorin \\ a,* and Marie-Isabelle Lannou ${ }^{\text {a,* }}$ \\ a Faculté de Pharmacie, CNRS UMR 8638, Université Paris Descartes, Université Sorbonne Paris-Cité, 4 avenue de l'observatoire, 75270 Paris Cedex 06, \\ France \\ Corresponding authors : Dr. Geoffroy Sorin: geoffroy.sorin@parisdescartes.fr \\ Dr. Marie-Isabelle Lannou: marie-isabelle.lannou@parisdescartes.fr
}

\section{ARTICLE INFO}

Article history:

Received

Received in revised form

Accepted

Available online

\section{Keywords:}

Keyword_1 Echinopines

Keyword_2 Sesquiterpenes

Keyword_3 Total synthesis

Keyword_4 Biosynthesis

Keyword_5 Tetracyclic skeleton

\section{ABSTRACT}

This review covers the different syntheses of two sesquiterpenes with unprecedented tetracyclic [3-5-5-7] framework, echinopines A and B. The synthetic strategies and ring-forming sequences are presented with emphasis on the methods for the stereoselective construction of the stereogenic centers in the echinopane skeleton.

2009 Elsevier Ltd. All rights reserved.

\section{Contents}

1. Introduction

2. Magauer, Mulzer and Tiefenbacher first total synthesis (2009)

3. Nicolaou and Chen total synthesis (2010) "Chen's first generation synthesis"

4. Chen's formal synthesis (2011) “Chen's second generation synthesis"

5. Chen's total synthesis (2011) “Chen's third generation synthesis"

6. Vanderwal's total synthesis (2012)

7. Liang's total synthesis (2013)

8. Misra's formal synthesis (2015)

9. Conclusion

\section{Introduction}

The synthesis of natural products of unique structure often allows innovation in strategy and can afford opportunities to develop new methodology. In this context, terpenoids occupy a unique position and pose significant synthetic challenges.

Echinopines A (1) and B (2), are two novel sesquiterpenoids isolated from the roots of Echinops spinosus, in 2008, by Shi and Kiyota. ${ }^{1}$ These minor metabolites $(0.12 \%$ yield $)$ are characterized by an unprecedented tetracyclic [3-5-5-7] skeleton. This complex architecture features five contiguous stereogenic centers, two of them being quaternary; noteworthy, the 7-membered cycle adopts a chair-like form (Figure 1). ${ }^{2}$

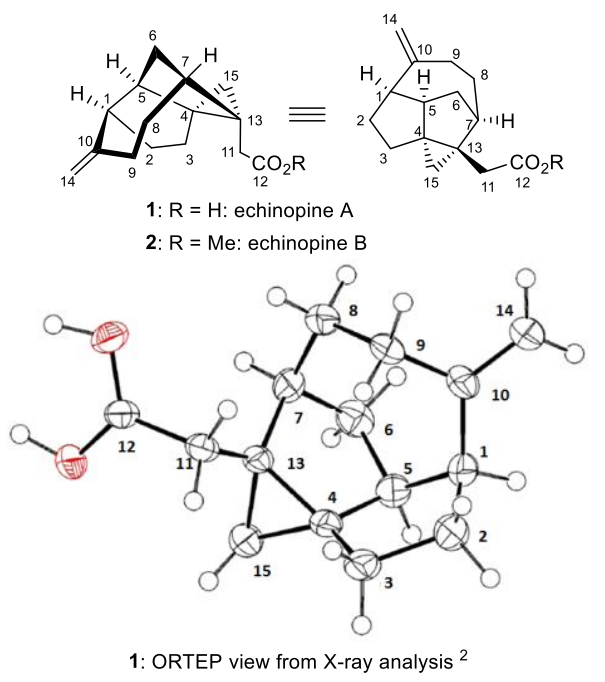

Figure 1. Structure of echinopines A (1) and B (2).

It has been suggested that the biosynthetic pathway of this unique echinopane framework may involve skeletal rearrangements from the guaiane type precursor $3 .{ }^{1}$ More particularly, a sequence including transformation of the [5-7] bicyclic ring system 4 into the [5-6-7] carbocation 5, was proposed for the construction of the [3-5-5-7] tetracyclic echinopane skeleton (Scheme 1). 

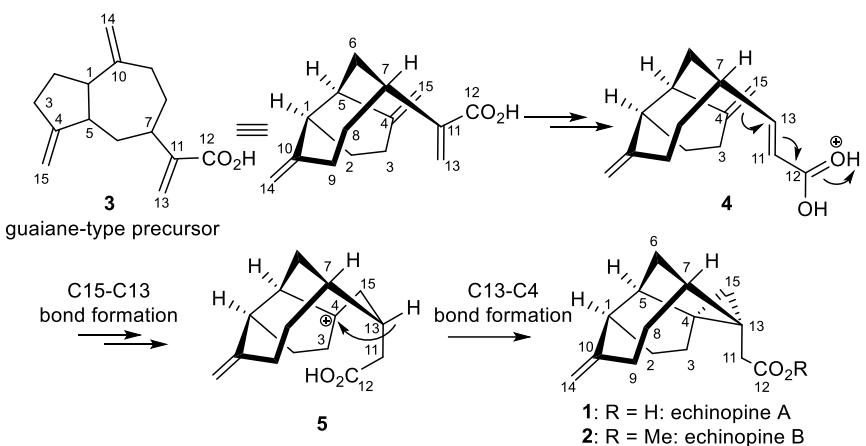

Scheme 1. Proposed biosynthetic pathway for the echinopane skeleton.

Although no biological activity has been uncovered so far, the original and complex structure of these natural products has motivated several research groups to embark on their total synthesis. Hence, only one year after their isolation, in 2009, Magauer, Mulzer and Tiefenbacher reported the first enantioselective total synthesis and determined the absolute configuration of these sesquiterpenes. ${ }^{2}$ Thereafter, in 2010, 2011 and 2012, Nicolaou, Chen and Vanderwal described four total or formal bioinspired syntheses of these two natural products. ${ }^{3-7}$ More recently, in 2013 and 2015, Liang and Misra respectively achieved one total and one formal synthesis proceeding through original sequences ${ }^{8}{ }^{89}$ However, it is important to note that only the first syntheses, developed by Tiefenbacher et al., Nicolaou and Chen have been performed in asymmetric form..$^{2-6}$

Design of strategies for the stereoselective synthesis of such complex skeletons is particularly challenging. Thus, in this review, which surveys the synthesis of echinopines, emphasis will be laid on the strategies and ring-forming sequences. An overview of the methods developed for the stereoselective construction of stereogenic centers in the echinopane skeleton will also be presented.

\section{Magauer, Mulzer and Tiefenbacher first total syn- thesis (2009)}

The first total synthesis of echinopines A (1) and B (2) was achieved by Magauer, Mulzer and Tiefenbacher in 2009. ${ }^{2}$ The strategy was based on the elaboration of the diquinane 8 bearing two cis-appendages at $\mathrm{C} 1$ and $\mathrm{C} 7$ (numbering identical to the final compounds). This intermediate was found suitable to build up the seven-membered ring by RCM and led to the tricyclic [5-5-7] intermediate 9.

In turn, the precursor $\mathbf{7}$ of bicycle $\mathbf{8}$, was easily prepared following a known procedure including a palladium chloridemediated transannular cyclization and subsequent enzymatic resolution from commercially available cyclooctadiene $\mathbf{6}^{10}$ Installation of the cyclopropane ring was accomplished at the end of the synthesis from [5-5-7] framework $\mathbf{1 0}$ (Scheme 2).

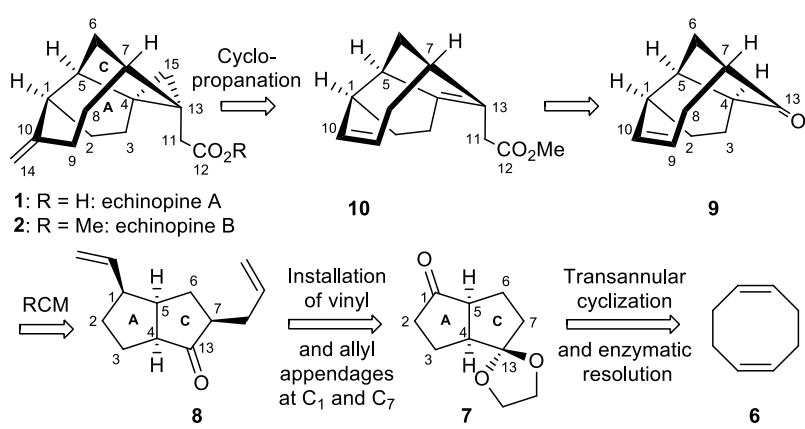

Scheme 2. Magauer, Mulzer and Tiefenbacher total synthesis: retrosynthetic analysis.

The synthesis started by converting cyclooctadiene 6 to optically active ketone 7 on multigram scale. Then, preparation of the RCM precursor $\mathbf{8}$ from bicyclic allylic alcohol 11 involved two key steps. The stereoselective installation of the vinyl moiety at $\mathrm{C} 1$ on the concave side of the bicyclo[3.3.0] octane core $\mathbf{1 1}$ was carried out through Myers [3,3]-sigmatropic rearrangement to give diastereomer 12 in $66 \%$ yield and 3.5:1 $d r .{ }^{11}$ The stereochemical outcome of this efficient reductive transposition of allylic alcohol 11 could be rationalized by steric interactions with the adjacent cyclopentane ring. Then, allylation at $\mathrm{C} 7$, next to the ketone function of 12, followed by epimerization under basic conditions, allowed the formation of the desired pure cis-diasteromer $\mathbf{8}$ (an easily separable 2.3:1 diastereomeric mixture was obtained).

The RCM reaction of the highly strained seven-membered ring of 8 smoothly occurred to yield tetracyclic adduct $\mathbf{9}$. With 9 in hand, late-stage functionalization began with the unusual Pdcatalyzed C2-homologation of a vinyltriflate with a ketene silyl acetal (formation of ester 10), ${ }^{12}$ followed by regioselective cyclopropanation to afford the tetracyclic derivative 13. Compound 13 was finally transformed into the target echinopines 1 and $\mathbf{2}$ (Scheme 3).
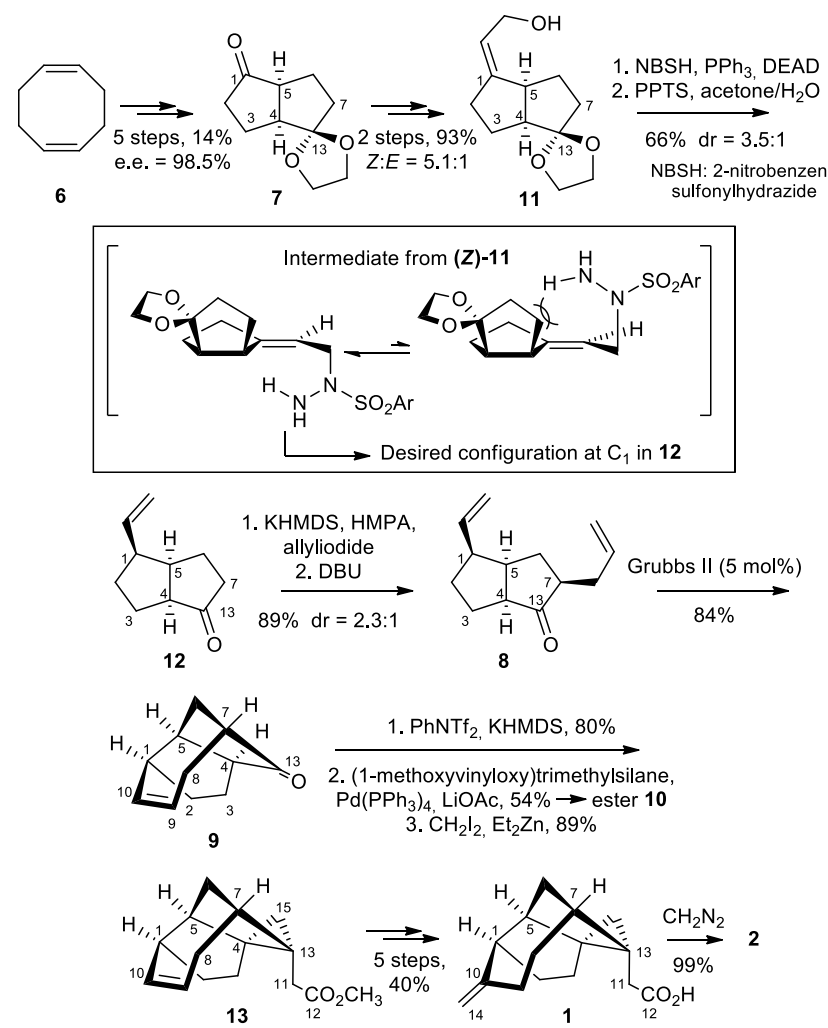

Scheme 3. Magauer, Mulzer and Tiefenbacher total synthesis. 
The total syntheses of echinopines A (1) and B (2) were achieved in an overall $1 \%$ yield for 20(21) steps. The relative configuration of $\mathbf{1}$ was confirmed by single crystal analysis, whereas the absolute configuration of $\mathbf{1}$ and $\mathbf{2}$ unambiguously follows from the synthesis.

\section{Nicolaou and Chen total synthesis (2010) "Chen's first generation synthesis"}

In 2010, inspired by the bond forming sequence suggested by the biosynthetic proposal of Shi and Kiyota, ${ }^{1}$ Nicolaou and Chen considered a chemically equivalent intramolecular cyclopropanation process i.e. a late stage transformation of the [56-7] tricyclic ring system 5 into [3-5-5-7] echinopane skeleton of 1 and 2. Unfortunately, this strategy met with failure primarily due to difficulties associated with the preparation of a suitable intramolecular cyclopropanation precursor. Therefore, in their first generation synthesis, they opted for a revised strategy that involved the simultaneous formation of the cyclopropane and one cyclopentane rings by means of a carbenoid intramolecular addition to the exocyclic olefinic bond of $\alpha$-diazo- $\beta$-ketoester $\mathbf{1 5}$, to afford the tricyclic [3-5-5] aldehyde $16{ }^{3}$ The cycloheptane was generated at a later stage through an intramolecular $\mathrm{SmI}_{2}$-mediated pinacol coupling reaction, from 16. Diazo compound 15 was elaborated from cyclohexenone 14 (Scheme 4).

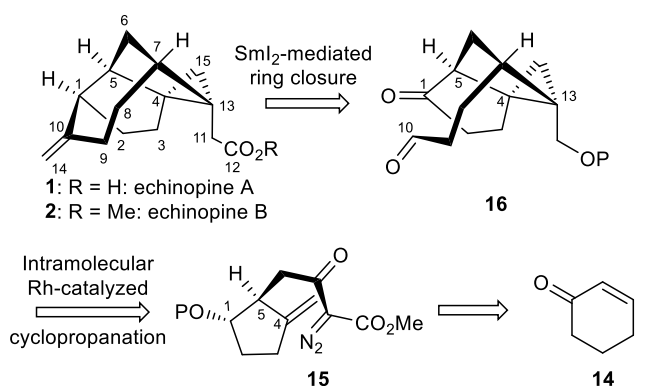

Scheme 4. Nicolaou and Chen total synthesis: retrosynthetic analysis.

Preparation of diazo ketoester 15 began from cyclohexenone 14 which was rapidly transformed into cyclopentyl allylic alcohol $\mathbf{1 8}$ by ring contraction of 17. Subsequent Johnson-Claisen rearrangement afforded carboxylic acid $\mathbf{1 9}$ as a 1.5:1 mixture of trans/cis C5 diastereomers after saponification. Conversion into desired diazo ketoester 15 was carried out by a two-step procedure in the presence of methyl potassium malonate followed by exposure to $p$-acetamidobenzenesulfenyl azide ( $p$-ABSA), with only a modest enhancement in the diastereomeric purity $(d r$ : 2.7:1). ${ }^{13}$ Therefore, an alternative synthesis of carboxylic acid 19 from cyclopentyl allylic alcohol 18, allowed to improve the diastereoselectivity to $7: 1$. The sequence involved [2,3] Wittig rearrangement of the alkenyl stannane derived from 18 and a onecarbon homologation of homoallylic alcohol 20 (Scheme 5).

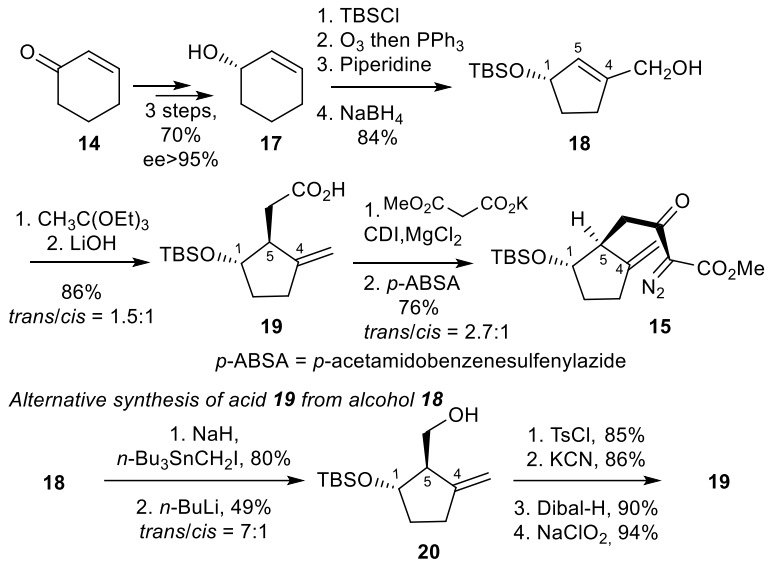

Scheme 5. Nicolaou and Chen total synthesis. Formation of the $\alpha$ diazo- $\beta$-ketoester intermediate $\mathbf{1 5}$.

At this stage, heating diazo compound $\mathbf{1 5}$ in the presence of $\mathrm{Rh}_{2}(\mathrm{OAc})_{4}$ (cat.) resulted in the formation of the desired tricyclic [3-5-5] system 21 in 70\% yield as a single diastereomer. The synthesis of allylic alcohol $\mathbf{2 3}$ from $\mathbf{2 1}$ required seven or six steps via vinyltriflate derivative 22. The next task was the elaboration of aldehyde 16. To this end, the double bond of allylic alcohol 23 was stereoselectively reduced to afford $\mathbf{2 4}$ and the side chain was extended to the required 3-carbon length in a six-step sequence (Scheme 6).
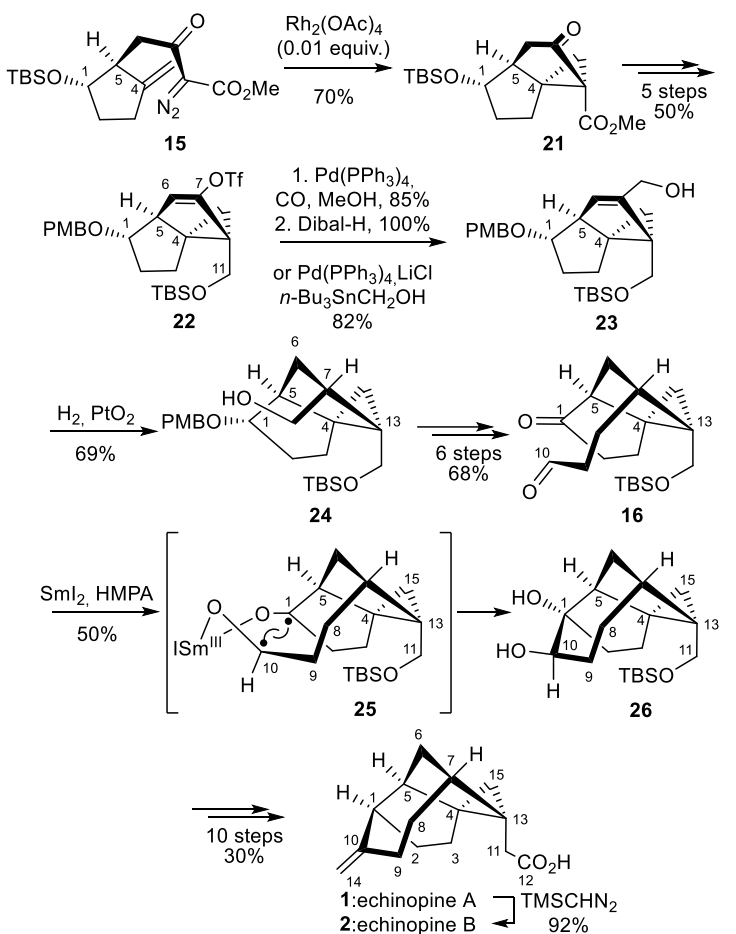

Scheme 6. Nicolaou and Chen total synthesis.

The forging of the remaining seven-membered ring was carried out by intramolecular pinacol coupling under $\mathrm{SmI}_{2}$-HMPA conditions, to afford the desired tetracyclic compound $\mathbf{2 6}$ as a single diastereomer in $50 \%$ yield, via the cyclic chelated transition state 25. ${ }^{14}$ Finally, the remaining functionalities (C14 of the exocyclic alkene and the $\mathrm{C} 12$-carboxylic acid) were introduced in a 10 step sequence.

This total synthesis of echinopines A (1) (and B (2)) was achieved in an overall $0.79 \%(0.73 \%)$ yield for 37 (38) steps. 


\section{Chen's formal synthesis (2011) "Chen's second gen- eration synthesis"}

The formal synthesis developed by Chen in 2011 featured another ring-forming sequence: the key step was based on the preparation of a [5-6-7] tricyclic intermediate 28 by means of the cycloisomerization/intramolecular Diels-Alder cascade reaction of an enyne-bearing substrate $\mathbf{2 7} .^{4,15,16}$ This tricyclic compound $\mathbf{2 8}$ was identified as a synthetic precursor of the [5-5-7] tricyclic ketone 9 already described by Magauer, Mulzer and Tiefenbacher, ${ }^{2}$ through a late-stage C4-C13 bond formation (Scheme 7).

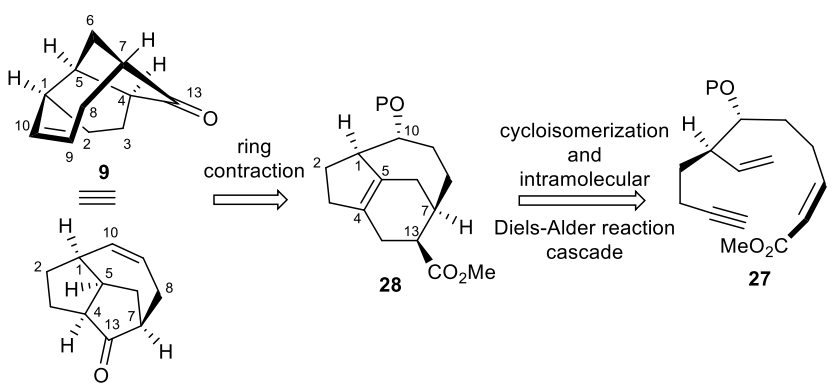

Scheme 7. Chen's formal synthesis: retrosynthetic analysis.

The acyclic precursor 27 was prepared in racemic and asymmetric forms. The preparation of racemic ( \pm )-27 has demonstrated the synthetic utility of Hosomi-Sakurai reaction: this reaction, involving allylsilane $\mathbf{2 9}$ and aldehyde $\mathbf{3 0}$ in the presence of $\mathrm{TiCl}_{4}$, afforded alcohol ( \pm )-31 in $75 \%$ yield as an inseparable mixture of diastereomers, in favor of the syn isomer ( $d r: 3: 1$ at C10). ${ }^{17}$ A six-step manipulation was subsequently performed to afford the desired intermediate $( \pm)-27$ (dr: 3:1 at C10). An auxiliary-controlled asymmetric aldol reaction involving thiazolidinethione $\mathbf{3 2}$ and aldehyde $\mathbf{3 0}$ in the presence of $\mathrm{TiCl}_{4}$ was next carried out to provide alcohol $\mathbf{3 3}$ as a single diastereomer, in $81 \%$ yield. Finally, enyne enolate $\mathbf{2 7}$ in optically active form was delivered in ten steps from $\mathbf{3 3}$ as a single diastereomer (Scheme 8).

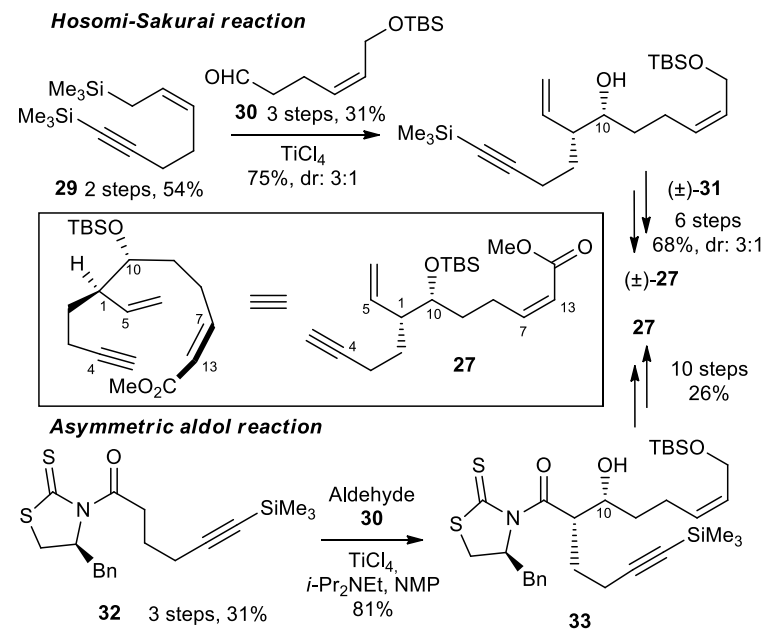

Scheme 8. Chen's formal synthesis: formation of enoate 27.

Upon treatment of 27 with $\mathrm{Pd}(\mathrm{OAc})_{2} / \mathrm{PPh}_{3}$ at $80^{\circ} \mathrm{C}$ followed by prolonged heating at $160^{\circ} \mathrm{C}$, the cycloisomerization/Diels Alder cascade reaction occurred to give the [5-6-7] tricycle 28 in $75 \%$ overall yield via intermediate 34. An endo transition state has been postulated. Noteworthy, the efficiency of the enyne cycloisomerization reaction in the absence of Thorpe-Ingold effect, is remarkable. Tricyclic intermediate $\mathbf{2 8}$ was next transformed into epoxy-ketone $\mathbf{3 6}$ through ketone 35, thus setting the stage for the ring contraction step. This was readily achieved by treatment of $\mathbf{3 6}$ with Montmorillonite K10 to deliver ketoaldehyde $\mathbf{3 7}$ as a single component. Subsequent basic aqueous work-up resulted in deformylation with concomitant partial desilylation, thus providing tricyclic ketone 38a $(\mathrm{P}=\mathrm{TBS}, 71 \%$ yield) and $\mathbf{3 8 b}(\mathrm{P}=\mathrm{H}, 23 \%$ yield $)$. At this stage, the targeted alkenyl ketone 9 was smoothly prepared in one step from $\mathbf{3 8 b}$, thus constituting a formal synthesis of echinopines A (1) and B (2) (Scheme 9). This synthesis of the optically active [5-5-7] tricyclic ketone 9, already described by Magauer, Mulzer and Tiefenbacher, was attained in an overall $0.6 \%$ yield for 25 steps. ${ }^{18}$

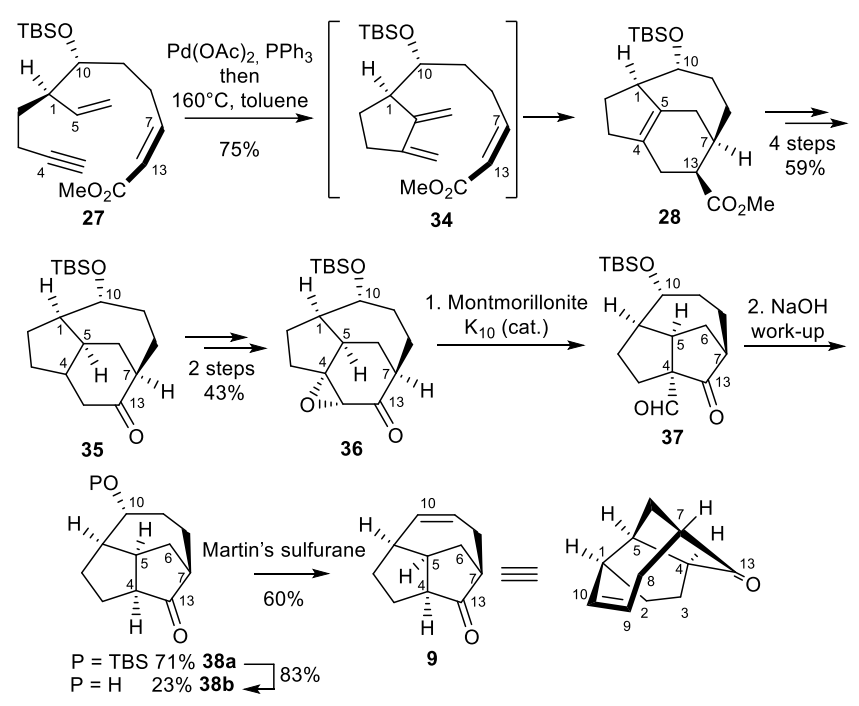

Scheme 9. Chen's formal synthesis.

\section{Chen's total synthesis (2011) "Chen's third genera- tion synthesis"}

Finally, Chen reported the realization of the late-stage intramolecular cyclopropanation process proposed in the biosynthetic pathway, through an extension of its second generation strategy, in a conceptually distinct [5-6-7] $\rightarrow[5-7] \rightarrow$ [3-5-5-7] ring-forming sequence to access echinopines $\mathbf{1}$ and $\mathbf{2}$. $^{5,6}$
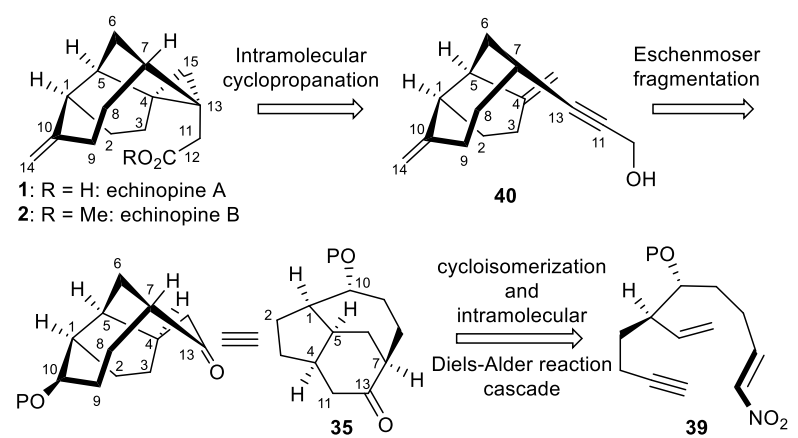

Scheme 10. Chen's total synthesis: retrosynthetic analysis.

In analogy with the proposed biosynthesis ( $c f$. Scheme 1), the [5-7] ene-yne $\mathbf{4 0}$ was established as intramolecular cyclopropanation precursor. Its elaboration involved an Eschenmoser fragmentation to cleave the $\mathrm{C} 4-\mathrm{C} 11$ bond of the [56-7] tricyclic ketone 35. This ketone was synthesized in accordance with the previously developed cycloisomerization/Diels-Alder pathway, from nitroalkene 39 (Scheme 10).

A $\mathrm{TiCl}_{4}$-mediated Hosomi-Sakurai reaction between allyl silane $\mathbf{2 9}$ and aldehyde $\mathbf{4 1}$ afforded the desired racemic alcohol in $74 \%$ yield as a mixture of $\mathrm{C} 10$ epimers $(d r: 7: 3)$ which was then 
protected as bis-TBS ether ( \pm -42. As described earlier in the second generation formal synthesis, the corresponding optically active bis-TBS ether $\mathbf{4 2}$ could be prepared as a single diastereomer, using a chiral auxiliary-based aldol approach, by reaction between thiazolidinethione $\mathbf{3 2}$ and aldehyde $\mathbf{4 1}$ and further functional group manipulations, via compound $\mathbf{4 3}$. Then, ene-yne $\mathbf{4 4}$ containing a nitroalkene moiety was obtained in five steps. Cycloisomerization/Diels-Alder cascade took place smoothly, under less drastic reaction conditions than previously required, to give nitro [5-6-7] tricycle $\mathbf{4 6}$ through intermediate $\mathbf{4 5}$. Subsequently, tricycle 46 was converted into ketone 35 by diimide reduction and subsequent Nef reaction. ${ }^{19}$ Therefore, compared to the formerly reported formal synthesis, a readily more straightforward access to $\mathbf{3 5}$ has been developed (Scheme 11).
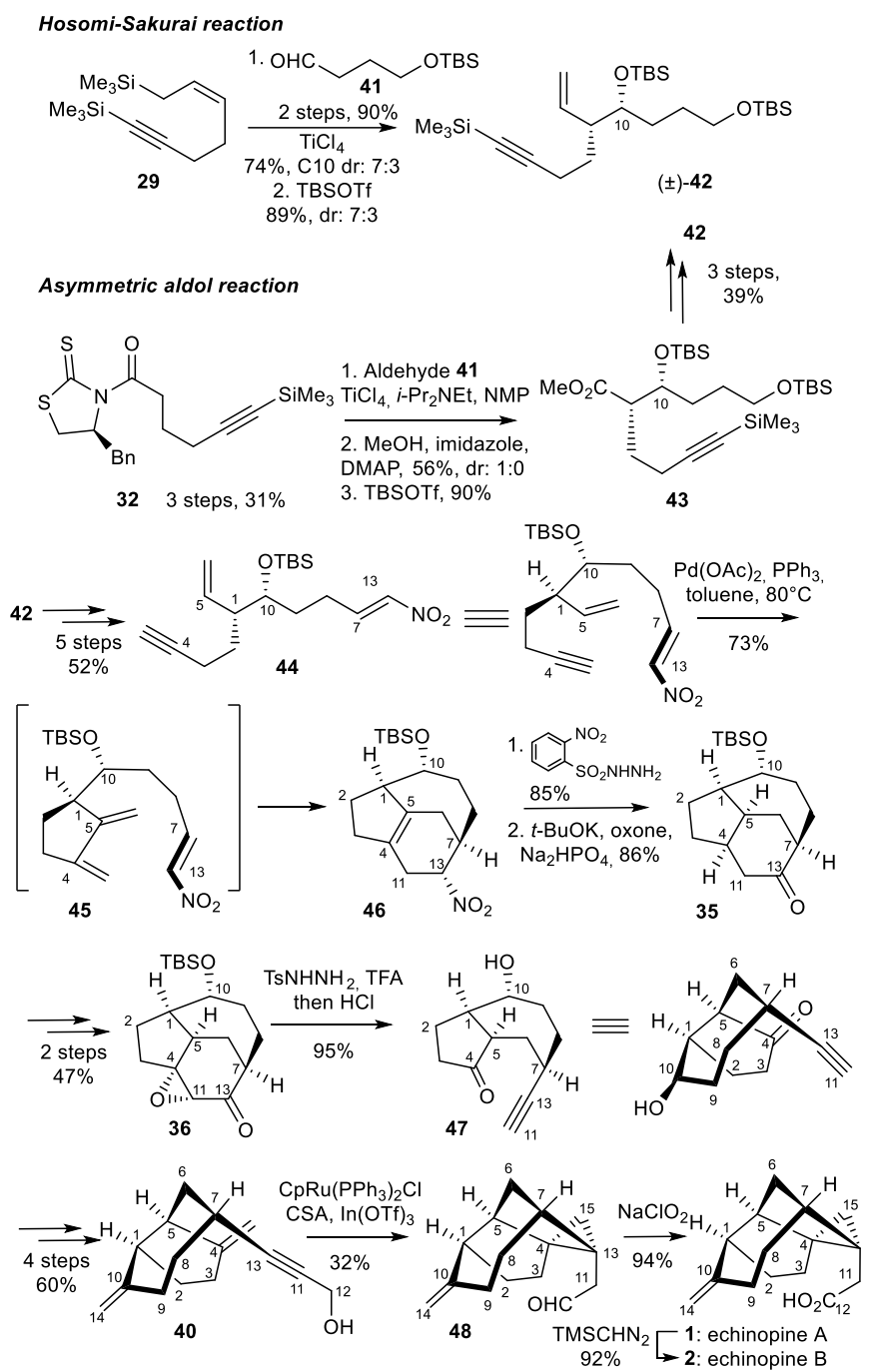

Scheme 11. Chen's total synthesis.

At this stage, an Eschenmoser fragmentation (treatment with $\mathrm{TsNHNH}_{2}$ followed by acidic work-up) of the corresponding [56-7] epoxy ketone $\mathbf{3 6}$ allowed for the formation of the [5-7] alkynylketone 47 through rupture of the six-membered cyclohexane ring at $\mathrm{C} 4-\mathrm{C} 11 .^{20}$

The final objective, i.e. the bioinspired [5-7] $\rightarrow$ [3-5-5-7] skeletal conversion with intramolecular cyclopropanation, was achieved from 40 under Trost's conditions $\left[\mathrm{CpRu}\left(\mathrm{PPh}_{3}\right)_{2} \mathrm{Cl}, \mathrm{CSA}\right.$, $\left.\operatorname{In}(\mathrm{OTf})_{3}\right]$ to deliver aldehyde $\mathbf{4 8}$ in $32 \%$ yield. Finally, an oxidation step provided echinopines $\mathbf{1}$ and 2 . $^{21}$
This asymmetric total synthesis was completed in $0.4(0.3) \%$ overall yield for 25(26) steps.

\section{Vanderwal's total synthesis (2012)}

The bioinspired total synthesis of racemic echinopine B ( \pm )-2 reported by Vanderwal, proceeded through a concise sequence including the one-step conversion of the cis-fused guaiane-like system ( \pm )-51 featuring a $\mathrm{C} 7$ propargylic ether into the natural product $( \pm)-2$. ${ }^{7}$ The strategy was inspired by a $\mathrm{PtCl}_{2}$-catalyzed reaction of alkene-tethered propargylic ethers described by Michelet, ${ }^{22}$ to efficiently prepare tricyclic [3-5-5] architectures. The propargylic ether precursor $( \pm)-\mathbf{5 1}$ arose from ester $( \pm)-\mathbf{5 0}$ and this cis-bicyclic structure was accessible from cycloheptenone $( \pm)$ 49, by annulation reaction onto C5 and C1 (Scheme 12).
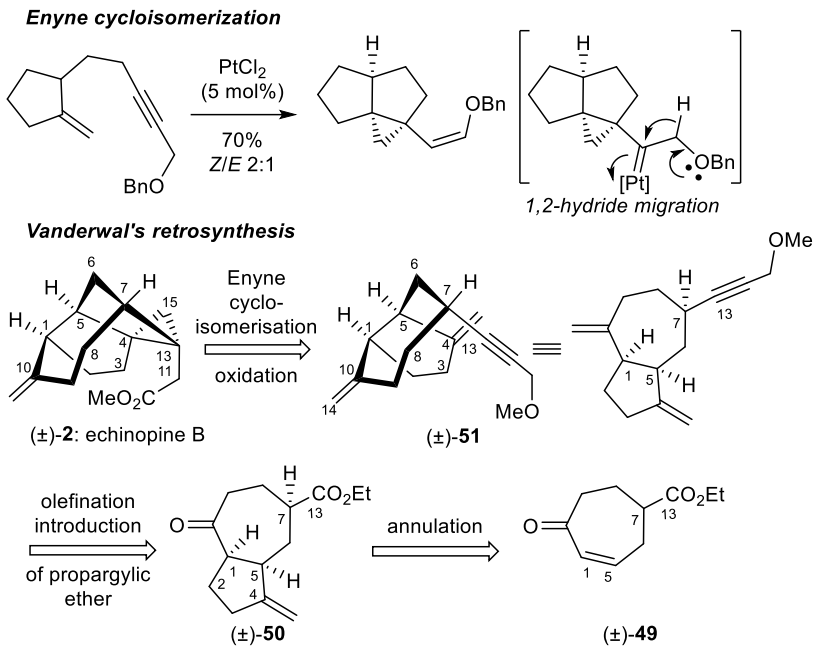

Scheme 12. Vanderwal's synthesis: retrosynthetic analysis.

The cycloheptenone ( \pm )-49 was easily prepared from ketoester $( \pm)-52$ by a modified Saegusa-type ring expansion in three steps. ${ }^{23}$ A stepwise route was further adopted for the annulation stage. Treatment of $( \pm)-\mathbf{4 9}$ with cuprate $\mathbf{5 3}$ provided adduct $( \pm)-\mathbf{5 4}$ as a 6.5:1 separable mixture of diastereomers in $88 \%$ yield; however, at this stage, the relative configuration of the major product could not be determined. The corresponding tosylate was then subjected to a base-mediated ring closure to afford cis-bicyclo[5.3.0]decane $( \pm)-50$ in $25-40 \%$ yield along with starting material. In the course of the synthesis of $( \pm)-56$ through Ohira-Bestmann alkynylation, an epimerization at $\mathrm{C} 7$ was observed yielding to two separable diastereomers in 4.5:1 proportions, the minor component corresponding to the major diastereomer of the starting material ( \pm )-55 (Scheme 13). 

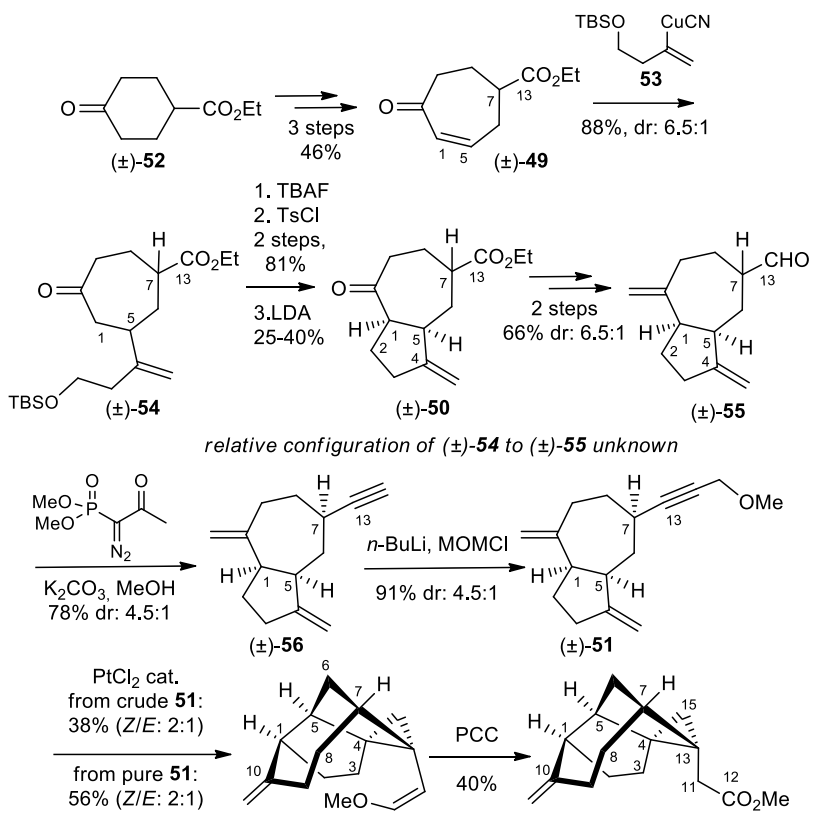

$( \pm)-57$

Scheme 13. Vanderwal's total synthesis.

After transformation of $( \pm)-\mathbf{5 6}$ into methyl ether $( \pm)-\mathbf{5 1}$, the cycloisomerization step was carefully examined. In the first experiments, subjection of the crude ene-propargylic ether ( \pm )-51 to $\mathrm{PtCl}_{2}$ (cat.) provided the desired echinopane skeleton $( \pm)-57$ in a modest $38 \%$ yield as a $2: 1$ mixture of $(Z) /(E)$ enol ether; the minor diastereomer of the starting material remaining unreacted.

Successful reaction can only occur if the C7 configuration allows the projection of the alkyne onto the concave face of the cis-fused bicyclic ring system. Therefore, it was hypothesized that the previous conjugate addition of $\mathbf{5 3}$ to $( \pm)-\mathbf{4 9}$, predominantly generated $( \pm)-54$ as the undesired diastereomer. Fortunately, the epimerization at the alkynylation step mainly corrected the $\mathrm{C} 7$ configuration and enabled the desired cycloisomerization to occur. In later experiments, the reaction was conducted from pure ( \pm )-51, thus providing $( \pm)-57$ in $56 \%$ yield. Final enol ether oxidation provided racemic echinopine B ( \pm )-2 in $40 \%$ yield.

This route to racemic echinopine B $( \pm)-2$ stands at 13 steps in $0.9 \%$ overall yield.

\section{Liang's total synthesis (2013)}

In 2013, Liang developed a new approach for the total synthesis of echinopines A (1) and B (2). ${ }^{8}$ The construction of the cyclopropane ring in tetracyclic framework $( \pm)-63$ bearing the core structure of the natural product, involved intramolecular 1,3dipolar cycloaddition reaction from diazo intermediate $( \pm)-61$ and subsequent irradiation of pyrazoline ( \pm )-62. Additionally, the synthesis featured rapid construction of the trans-decalin intermediate ( \pm -58 through an aldol-Henry cascade reaction from ketone ( \pm -52 and subsequent transformation to cis-fused bicyclo[5.3.0]decane ring system ( \pm )-59 by means of a TiffeneauDemjanov rearrangement. Further group manipulation provided $( \pm)-60$ as precursor of $( \pm)-61$ for the 1,3-dipolar cycloaddition reaction (Scheme 14).
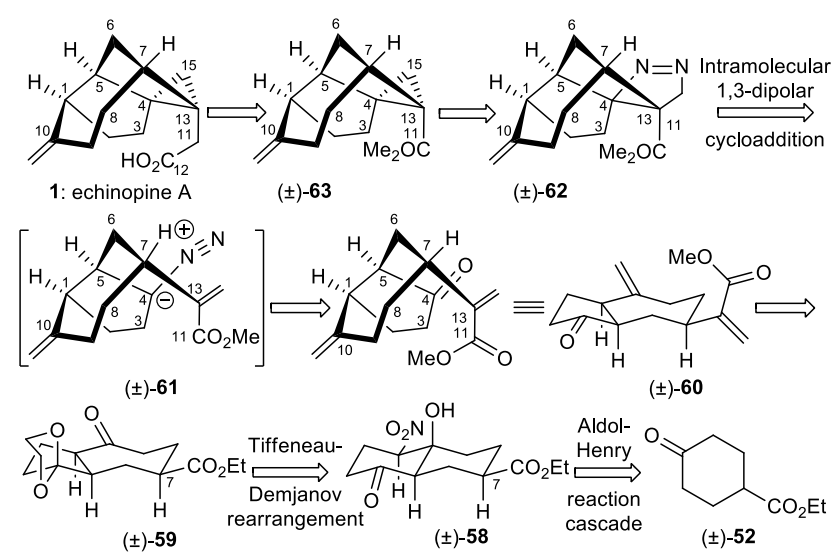

Scheme 14. Liang's synthesis: retrosynthetic analysis.

An aldol-Henry reaction cascade between enolate of ketone $( \pm)-52$ and 4-nitrobutanal 64 followed by oxidation and equilibration allowed the isolation of the desired trans-decalin $( \pm)$ 58 in $46 \%$ yield along with epimer at C7 in 5\% yield. ${ }^{24}$ Notably, this robust reaction sequence can be readily scaled up to produce over $10 \mathrm{~g}$ of $( \pm)-\mathbf{5 8}$ in one batch. After protection and reduction, a Tiffeneau-Demjanov rearrangement generated the cis-fused 5,7carbocycle $( \pm)-\mathbf{5 9}$ in $77 \%$ from $( \pm)-\mathbf{6 5}$, with complete stereochemical control. ${ }^{25}$ At this stage, the key "cross-ring" 1,3dipolar cycloaddition reaction was examined from ketone $( \pm)-\mathbf{6 0}$, elaborated from $( \pm)-\mathbf{5 9}$ in a six step sequence. ${ }^{26}$ The cycloaddition occurred smoothly by heating the corresponding tosylhydrazone to give the required pyrazolone $( \pm)-62$ in $68 \%$ yield. Next, irradiation of $( \pm)-62$ led to the tetracyclic compound $( \pm)-63$, advanced intermediate in the total synthesis of echinopines $\mathbf{1}$ and 2. ${ }^{27}$ The targeted natural products were finally isolated after homologation in $39 \%$ yield (Scheme 15).

This total synthesis in racemic version has been accomplished in $2.2 \%$ overall yield for 18 steps.
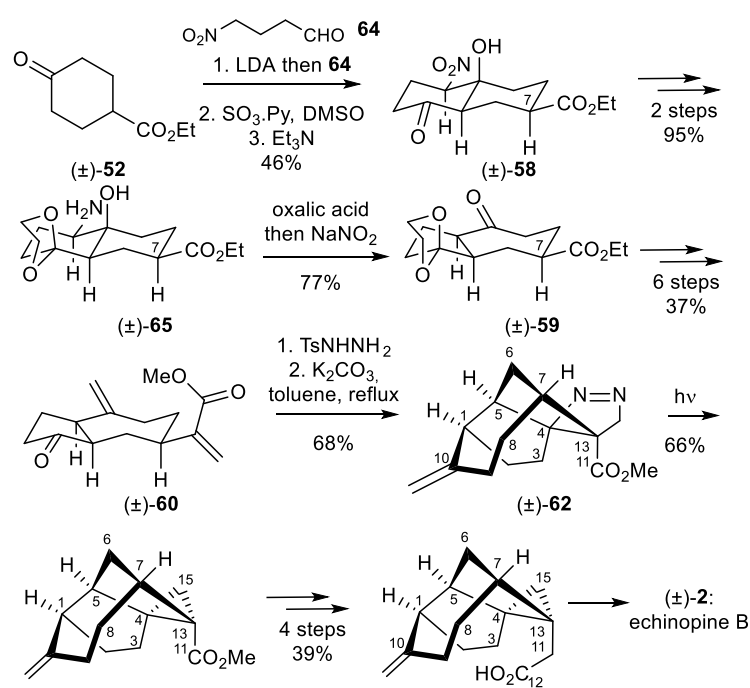

$( \pm)-63$

(t)-1: echinopine $\mathrm{A}$

Scheme 15. Liang's total synthesis.

\section{Misra's formal synthesis (2015)}

Very recently (in 2015), Misra described a formal synthesis of racemic echinopines $( \pm)-\mathbf{1}$ and $( \pm)-\mathbf{2}$ using a distinctly different strategy from those previously reported. ${ }^{9}$ Hence, the advanced tricyclic intermediate $( \pm)-\mathbf{1 0}$, already reported by Magauer, Mulzer and Tiefenbacher in $2009,{ }^{2}$ was obtained by a regioselective 5-exo 
trig intramolecular radical cyclization from xanthate $( \pm)$-69. In turn, the bicyclo[4.2.1]nonane precursor $( \pm)$ - $\mathbf{6 8}$ was easily built by employing a photochemical $\mathrm{Cr}(0)$-promoted $[6 \pi+2 \pi]$ cycloaddition reaction of alkyne $\mathbf{6 6}$ and tricarbonyl chromium-(0) complex 67 (Scheme 16). ${ }^{28}$

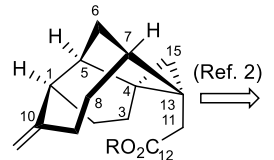

$( \pm)-1$ and $( \pm)-2$

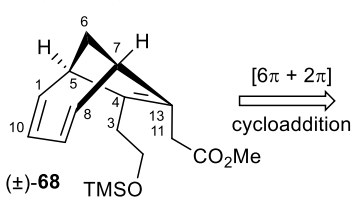

-10

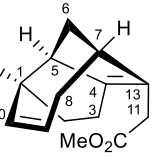

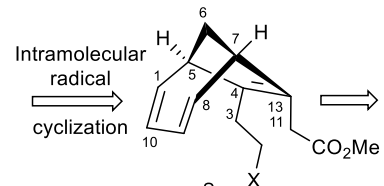

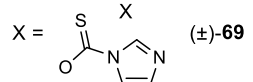

67

66

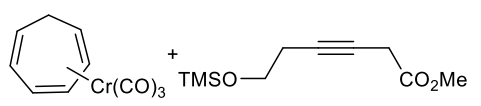

Scheme 16. Misra's formal synthesis: retrosynthetic analysis.

The requisite alkynoate $\mathbf{6 6}$ was smoothly prepared on multigram scale by means of a $\mathrm{CuI}$ catalyzed $\mathrm{C}-\mathrm{H}$ insertion method reported by $\mathrm{Fu}$ from terminal alkyne 70. ${ }^{29}$ Then, a dilute solution of chromium complex 67 and alkyne 66 was irradiated using a 450-W medium-pressure mercury vapor lamp to afford the bicyclic intermediate $( \pm)-71$ in $71 \%$ yield. Numerous conditions were tested for the optimization of the key radical cyclization involving an inactivated cyclic diene. Finally, from xanthate $( \pm)$ 69, the tricyclic methyl ester derivative $( \pm)-10$ was obtained in an acceptable $61 \%$ yield, through the slow addition of a $\mathrm{Bu}_{3} \mathrm{SnH} / \mathrm{AIBN}$ mixture to a refluxing dilute toluene solution (Scheme 17).
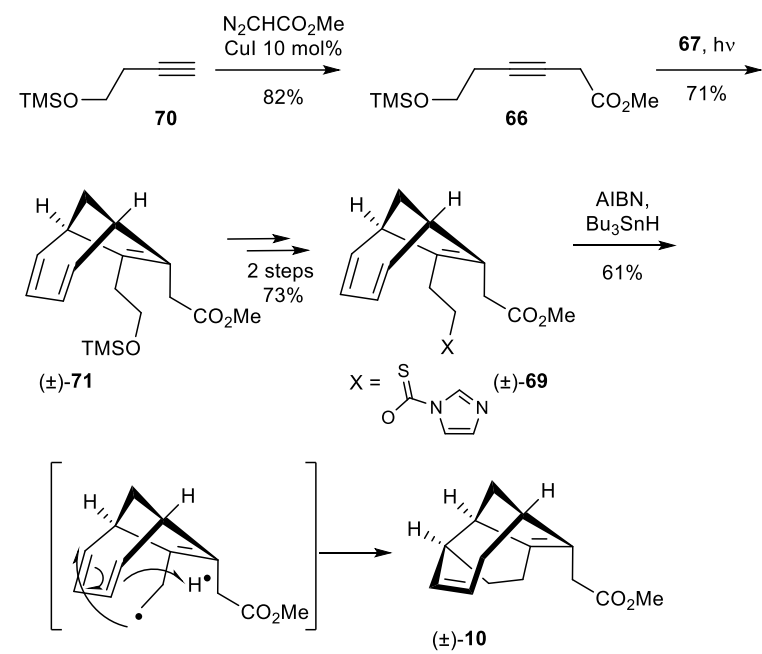

Scheme 17. Misra's formal synthesis.

Thus, a formal synthesis of racemic echinopines A and B has been achieved in a five step sequence ( $26 \%$ overall yield) to the known intermediate $( \pm)-\mathbf{1 0} .^{30}$

\section{Conclusion}

In this account, the different syntheses of echinopines have been highlighted and discussed. A number of innovative and elegant strategies (seven) have been developed to succeed in this synthetic challenge. For clarity, the different synthetic pathways established for the set-up of the echinopane framework are summarized below (Scheme 18).

One key feature of the echinopine synthesis is clearly the establishment of the original [3-5-5-7] skeleton through conceptually contrasting ring-forming sequences. Remarkably,

four of the seven approaches are bioinspired, ${ }^{3-7}$ including the highly challenging simultaneous formation of the cyclopropane ring and one of the cyclopentane rings, generally conducted at a late-stage of the synthesis.

Finally, it is interesting to mention that the most recent syntheses have been elaborated in a sake of originality, albeit in racemic form.

Magauer, Mulzer and Tiefenbacher, 2009, total synthesis, $20(21)$ steps, $1 \%$ overall yield Sequence: [8] $>$ [5-5] $\rightarrow>[5-5-7]->[3-5-5-7]$

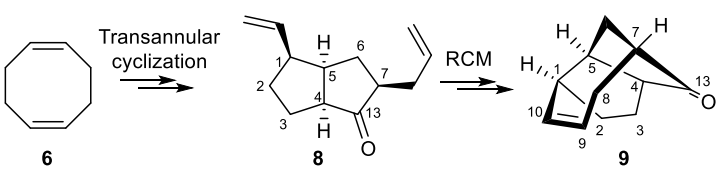

[8] [5-5]

[5-5-7]

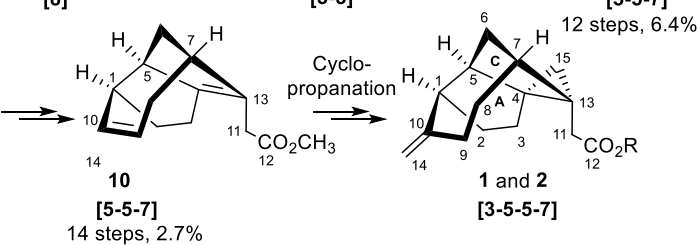

Nicolaou and Chen, 2010, "first generation synthesis",

total synthesis, $37(38)$ steps, $0.79 \%(0.73 \%)$ overall yield

Sequence: $[6] \rightarrow[5] \rightarrow[3-5-5] \rightarrow[3-5-5-7]$

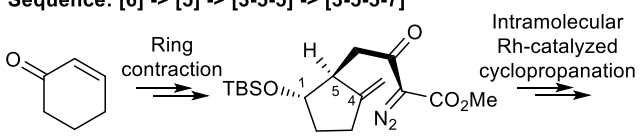

14

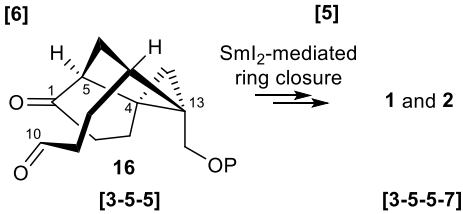

Chen, 2011, "second generation synthesis",

formal synthesis 25 steps, $1.0 \%$ overall yield

Sequence: [5-6-7] $\rightarrow$ [5-5-7]

TBSO cycloisomerization

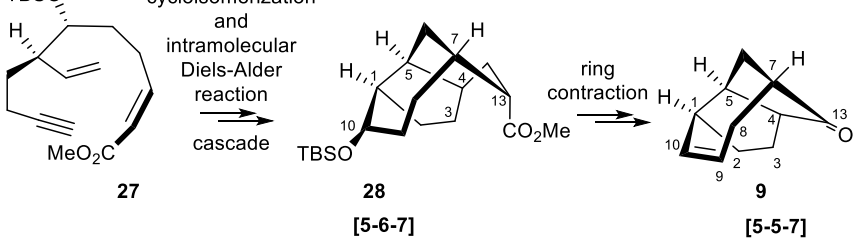

$$
\underset{15 \%^{2}}{\stackrel{8 \text { steps }}{\longrightarrow}} \quad 1
$$

Chen, 2011, "third generation synthesis",

total synthesis $25(26)$ steps, $0.5(0.4) \%$ overall yield Sequence: [5-6-7] $\rightarrow[$ [5-7] $\rightarrow$ [3-5-5-7]

TBSO

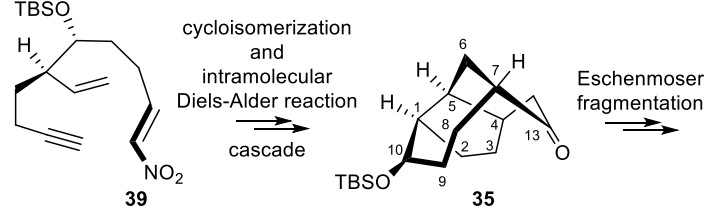

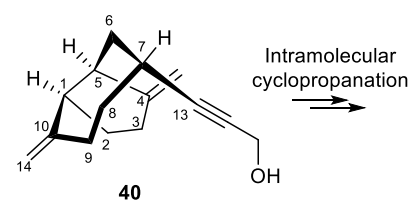

[5-7]

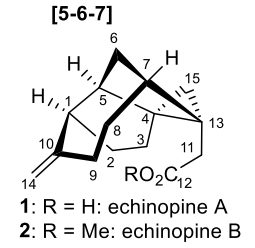

[3-5-5-7] 


\section{Vanderwal, 2012}

total racemic synthesis, 13 steps, $0.9 \%$ overall yield Sequence $[0] \rightarrow[7] \rightarrow[5-7] \rightarrow[3-5-5-7]$

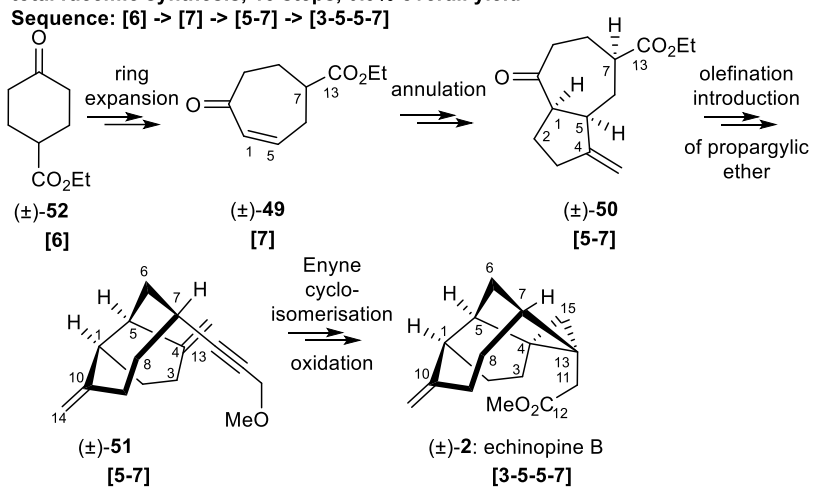

Liang, 2013

total racemic synthesis, 18 steps, $2.2 \%$ overall yield

Sequence: [6] $>[6-6]->[5-7]->[3-5-5-7]$

O

$\underbrace{\stackrel{\substack{\text { Aldol- } \\ \text { reaction } \\ \text { cascade }}}{\longrightarrow}}_{\mathrm{CO}_{2} \mathrm{Et}}$

$( \pm)-5$

[6]

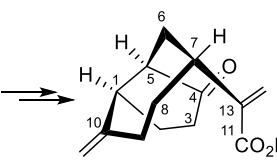

$( \pm)-60$

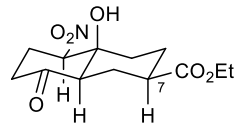

$( \pm)-58$

[6-6]

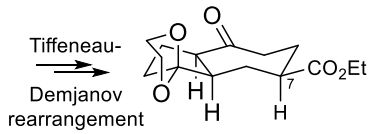

${ }_{[5-7]}^{( \pm)-59}$

Intramolecular 1,3-dipolar cycloadditio $\vec{\longrightarrow}$ Intramolecular

[5-7]

[3-5-5-7]

Misra, 2015

formal racemic synthesis, 5 steps, $26 \%$ overall yield

Sequence: $[7] \rightarrow[5-7]->[5-5-7]$

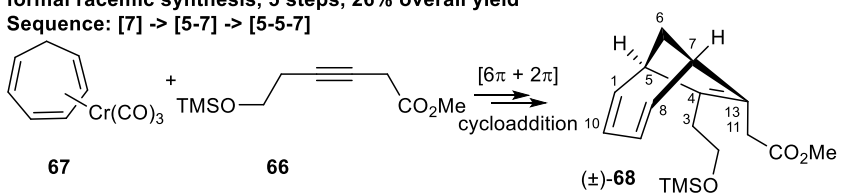

67

[7]

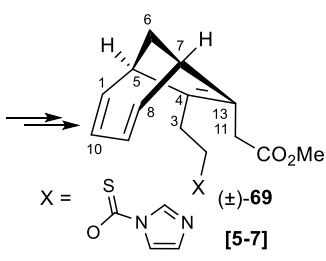

[5-7]

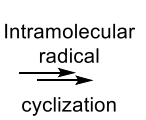

cyclization

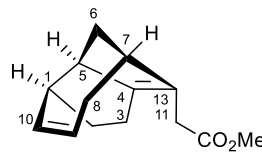

$( \pm)-10$

[5-5-7]

$$
\underset{36 \%{ }^{2}}{\stackrel{6 \text { steps }}{\longrightarrow}} \quad( \pm)-1
$$

Scheme 18. Overview of the synthetic strategies towards the echinopines and ring-forming sequences.

\section{References and notes}

1. Dong, M.; Cong, B.; Yu, S.-H.; Sauriol, F.; Huo, C.-H.; Shi, Q.W.; Gu, Y.-C.; Zamir, L. O.; Kiyota, H. Org. Lett. 2008, 10, 701704

2. Magauer, T.; Mulzer, J.; Tiefenbacher, K. Org. Lett. 2009, 11, 5306-5309.

3. Nicolaou, K. C.; Ding, H.; Richard, J.-A.; Chen, D. Y.-K. J. Am. Chem. Soc. 2010, 132, 3815-3818.

4. Peixoto, P. A.; Severin, R.; Tseng, C.-C.; Chen, D. Y.-K. Angew. Chem., Int. Ed. 2011, 50, 3013-3016.
5. Peixoto, P. A.; Richard, J.-A.; Severin, R.; Chen, D. Y.-K. Org. Lett. 2011, 13, 5724-5727.

6. Chen, D. Y.-K. Synlett 2011, 2459-2481.

7. Michel, T. D.; Dowling, M. S.; Vanderwal, C. D. Angew. Chem., Int. Ed. 2012, 51, 7572-7576.

8. Xu, W.; Wu, S.; Zhou, L.; Liang, G. Org. Lett. 2013, 15, 1978-1981

9. De, S.; Misra, S.; Rigby, J. H. Org. Lett. 2015, 17, 3230-3232.

10. (a) Perard-Viret, J.; Rassat, A. Tetrahedron: Asymmetry 1994, 5 , 1-4. (b) Zhong, Y.-W.; Lei, X.-S.; Lin, G.-Q. Tetrahedron: Asymmetry 2002, 13, 2251-2255. (c) Lemke, K.; Ballschuh, S.; Kunath, A.; Theilm, F. Tetrahedron: Asymmetry 1997, 8, 20512055.

11. (a) Myers, A. G.; Zheng, B. Tetrahedron Lett. 1996, 37, 48414844. Myers, A. G.; Zheng, B.; Movassaghi, M. J. Org. Chem. 1997, 62, 7507-7507

12. (a) Carfagna, C.; Musco, A.; Sallese, G.; Santi, R.; Fiorani, T. J. Org. Chem. 1991, 56, 261-263. Mallinger, A.; Le Gall, T.; Mioskowski, A J. Org. Chem. 2009, 74, 1124-1129.

13. Baum, J. S.; Shook, D. A.; Davies, H. M. L.; Smith, D. H. Synth. Commun. 1987, 17, 1709-1716.

14. For selected reviews on the use of samarium diiodide in chemical synthesis, see: (a) Nicolaou, K. C.; Ellery, S. P.; Chen, J. S. Angew. Chem., Int. Ed. 2009, 48, 7140-7165. (b) Edmonds, D. J.; Johnston, D.; Procter, D. J. Chem. Rev. 2004, 104, 3371-3403. (c) Kagan, H. B. Tetrahedron 2003, 59, 10351-10372. (d) Molander, G. A.; Harris, C. R. Chem. Rev. 1996, 96, 307-338.

15. Nicolaou, K. C.; Snyder, S. A.; Montagnon, T.; Vassilikogiannakis, G. Angew. Chem. Int. Ed. 2002, 41, 16681698.

16. Michelet, V.; Toullec, P. Y.; Genet, J.-P Angew. Chem. Int. Ed. 2008, 47, 4268-4315.

17. (a) Hosomi, A.; Endo, M.; Sakurai, H. Chem. Lett. 1976, $941-$ 942; (b) Fleming, I.; Dunoguès, J.; Smithers, R. Org. React. 1989, 37, 57-575; (c) Fleming, I. in Comprehensive Organic Synthesis; Trost, B. M. and Fleming, I., Eds.; Pergamon Press: Oxford, 1991, Vol. 2, pp 563-593.

18. The synthesis of ketone 9 was previously achieved by Tiefenbacher et al. in an overall $6.4 \%$ yield for 12 steps. Subsequent elaboration of echinopine A 1 from 9 was completed in $15 \%$ yield for 8 steps by the same authors.

19. Ballini, R.; Petrini, M. Tetrahedron 2004, 60, 1017-1047.

20. Eschenmoser, A.; Felix, D.; Ohloff, G. Helv. Chim. Acta 1967, 50, 708-713.

21. Trost, B. M.; Breder, A.; O'Keefe, B. M.; Rao, M.; Franz, A. W. J. Am. Chem. Soc. 2011, 133, 4766-4769.

22. Ye, L.; Chen, Q.; Zhang, J.; Michelet, V. J. Org. Chem. 2009, 74, 9550-9553

23. Ito, Y.; Fujii, S.; Saegusa, T. J. Org. Chem. 1976, 41, 2073-2074.

24. For a review on the Henry reaction, see: Luzzio, F. A. Tetrahedron 2001, 57, 915-945.

25. For a review on the Tiffeneau-Demjanov rearrangement, see: Fattori, D.; Henry, S.; Vogel, P. Tetrahedron 1993, 49, 16491664.

26. There is only a single instance of the use of intramolecular cycloaddition of a diazo alkane to an alkene in natural product synthesis; see: Schultz, A. G.; Puig, S. J. Org. Chem. 1985, 50, 915-916.

27. Taber, D. F.; Guo, P. J. Org. Chem. 2008, 43, 9479-9481.

28. Rigby, J. H. Tetrahedron 1999, 55, 4521-4538.

29. Suarez, A.; Fu, G. C. Angew. Chem., Int. Ed. 2004, 43 , 3580-3582.

30. The synthesis of optically active [5-5-7] skeleton $\mathbf{1 0}$ was already achieved by Tiefenbacher $e t a l$. in an overall $2.7 \%$ yield for 14 steps. Further elaboration of echinopine A $\mathbf{1}$ from $\mathbf{1 0}$ was completed in $36 \%$ yield for 6 steps by the same authors. 